\title{
Phthalate esters contamination in soil and plants on agricultural land near an electronic waste recycling site
}

\author{
Ting Ting Ma $\cdot$ Peter Christie $\cdot$ Yong Ming Luo $\cdot$ \\ Ying Teng
}

Received: 22 February 2012/Accepted: 5 December 2012/Published online: 18 December 2012

(C) Springer Science+Business Media Dordrecht 2012

\begin{abstract}
The accumulation of phthalic acid esters (PAEs) in soil and plants in agricultural land near an electronic waste recycling site in east China has become a great threat to the neighboring environmental quality and human health. Soil and plant samples collected from land under different utilization, including fallow plots, vegetable plots, plots with alfalfa (Medicago sativa L.) as green manure, fallow plots under long-term flooding and fallow plots under alternating wet and dry periods, together with plant samples from relative plots were analyzed for six PAE compounds nominated as prior pollutants by USEPA. In the determined samples, the concentrations of six target PAE pollutants ranged from $0.31-2.39 \mathrm{mg} / \mathrm{kg}$ in soil to $1.81-5.77 \mathrm{mg} / \mathrm{kg}$ in various plants (dry weight/ DW), and their bioconcentration factors (BCFs)
\end{abstract}

T. T. Ma · Y. M. Luo · Y. Teng

Key Laboratory of Soil Environment and Pollution Remediation, Institute of Soil Science, Chinese Academy of Sciences, Nanjing 210008, China

T. T. Ma · Y. M. Luo · Y. Teng

Graduate University of the Chinese Academy of Sciences, Beijing 100049, China

P. Christie

Agri-Environment Branch, Agri-Food and Biosciences Institute, Newforge Lane, Belfast BT9 5PX, UK

\section{Y. M. Luo ( $\square)$}

Yantai Institute of Costal Zone Research, Chinese Academy of Sciences, Yantai 264003, China

e-mail: ymluo@yic.ac.cn ranged from 5.8 to 17.9. Health risk assessments were conducted on target PAEs, known as typical environmental estrogen analogs, based on their accumulation in the edible parts of vegetables. Preliminary risk assessment to human health from soil and daily vegetable intake indicated that DEHP may present a high-exposure risk on all ages of the population in the area by soil ingestion or vegetable consumption. The potential damage that the target PAE compounds may pose to human health should be taken into account in further comprehensive risk assessments in e-waste recycling sites areas. Moreover, alfalfa removed substantial amounts of PAEs from the soil, and its use can be considered a good strategy for in situ remediation of PAEs.

Keywords Phthalic acid esters · Soil contamination · Edible vegetables $\cdot$ Health risk assessment . Electronic waste recycling

\section{Introduction}

Electronic waste recycling and dismantling has become an important industrial activity to the local economy in Taizhou, Zhejiang province, east China. However, arbitrary and improper recycling methods have resulted in multiple environmental contamination proceeded by heavy metals, polychlorinated biphenyls (PCBs), polycyclic aromatic hydrocarbons 
(PAHs), polychlorinated dibenzo-p-dioxins/dibenzofurans (PCDD/Fs) and polybrominated diphenyl ethers (PBDEs) (Chen et al. 2008; Li 2008a; Ni et al. 2008). DnBP, DEHP and DnOP are supposed to be the three most frequently detected phthalic acid ester (PAE) compounds in most of the electrical wastes (Zhang et al. 2010a, b), which makes it explainable for the discovery of PAE compounds in agricultural soils in Taizhou with elevating levels in recent years. Ever since 2009, reported total concentrations of five dominant PAE compounds in Taizhou ranged from 12.6 to $46.7 \mathrm{mg} / \mathrm{kg}$ soil DW, far higher than the soil allowable concentration in the United States, about $7 \mathrm{mg} / \mathrm{kg}$ soil DW, and contamination by PAE compounds has recently become a problem that could not be neglected in the Taizhou area (Liu et al. 2009; Liu et al. 2010a; Zhang et al. 2010a, b).

As globally used plasticizers, PAEs have aroused considerable public concern for several decades due to a number of associated environmental problems (Matsumoto et al. 2008; Cai et al. 2008b; Liu et al. 2010b; Nanni et al. 2011). Extensive use in industrial activity and daily life has resulted in their ubiquitous pollution to air, soils and waters, especially in China (Zeng et al. 2009a, b). There is also great possibility of PAE compounds being accumulated in agricultural soils and absorbed by crops and vegetables to the edible parts causing direct damage to plants and contamination of the human food chain (Wang et al. 2008; Chi 2009; Liao et al. 2009). In addition, some PAE compounds have been recognized as endocrine disrupters and environmental carcinogens, teratogens and mutagens (Gray et al. 2000; Duty et al. 2003). In 1999, six PAE compounds were nominated by USEPA as priority pollutants and three of them, specifically DMP, DEP and DnOP, have subsequently been listed as priority pollutants in China.

In all the factors that affected the total content of target PAE pollutants in soil samples, which could also be deemed as the pollution status of all the investigated plots, different land utilization ways played an important role. For example, most PAE compounds are found to be much easier to degrade under aerobic environmental conditions but anaerobiosis created by flooding greatly retarded the degradation (Shanker et al. 1985), which means the total content of the target pollutants in long-term flooding plot could be higher than non-flooded plots. The content of PAEs from a business area (BU), classical garden (CL), culture and educational area (CU), large public green space (LA), residential area $(\mathrm{RE})$ and roadside area $(\mathrm{RO})$ in Beijing showed decreasing trends from the center of the city to the suburbs, which indicated that naturally different land utilizations lead to various soil contaminations of PAEs (Xia et al. 2011). It has been published that alfalfa (Medicago sativa L.) could significantly accumulate PAE compounds from soil as a critical way of phytoremediation (Ma et al. 2012a). Vegetables such as rape could also concentrate PAE compounds from soil (Cai et al. 2008a). Under different land utilization mode in farm land of adjacent area, the contamination status of soil and plant samples in selected plots could be revealed.

Current studies on PAEs are mostly focused on their direct chronic toxicity. However, it has been documented that PAE compounds with high $K_{\mathrm{ow}}$ (log $K \geq 5)$ and high $K_{\text {oa }}\left(\log K_{\text {oa }}=6-12\right)$ are likely to be concentrated (Kelly et al. 2007), and accordingly, PAEs with $\log K_{\text {ow }}=2-7$ and $\log K_{\text {oa }}>6$ may be concentrated or magnified in terrestrial organisms and in the human body (Cai et al. 2003; Li 2008b). Bioconcentration factors (BCFs) could illustrate the comparative cumulative effects of pollutants in different organisms along the food chain. Different ways of exposure for residents of urban areas near contaminated sites to target chemicals may be substantial which makes it more indispensable to carry out health risk assessment in these areas. In consideration of the difficulty of acquiring overall pollution information, simplified health risk assessment by evaluation of soil contact and food intake make great sense in revealing the effects of pollution status in investigated area to residents nearby.

In this study, the concentrations of six PAEs in soil and plant samples were determined to gain a clear idea of the typical PAE compounds contamination status in soil and plant species growing in fields near an e-waste dismantling area; beyond ranking the sources of uncertainty and variability, this study assessed the probability of PAEs health risk based on the calculated indices of vegetables produced in this area; soil PAE compounds content by evaluating both the oral reference dose (RfDo) and tolerable daily intake (TDI) of the target pollutants should be put more emphasis on in the prospective health assessment process of the multicontaminated e-waste dismantling areas. 


\section{Methods and materials}

\section{Sampling}

In winter of 2010, over 110 samples of soil (paddy soil) and plant material were collected from an agricultural area about $250 \mathrm{~m}$ from an electronic waste dismantling site at Luqiao township, Taizhou city, located at $28^{\circ} 22^{\prime \prime} \mathrm{N}, 121^{\circ} 22^{\prime \prime \prime} \mathrm{E}$ in Zhejiang Province, east China (Fig. 1). The $\mathrm{pH}$ value of soil in this neighborhood was 5.56, organic matter content was $36.5 \mathrm{~g} / \mathrm{kg}$ and total nitrogen, phosphorus and potassium were $1.96,0.56$ and $23.1 \mathrm{~g} / \mathrm{kg}$, respectively.

The total area has been continuously cropped as the designed pattern for more than 1 year was about $37 \mathrm{~m} \times 30 \mathrm{~m}$ and a 2-m gap between every two plot. Further details could be referred to the schematic drawings (Fig. 2). Four different types of plot in triplicate were arranged randomly, (1) control fallow plots with no plants present (CK); (2) vegetable plots (VP) in which carrot, soybean, cauliflower, radish and pak choi were intercropped in rows; (3) green manure plots (GP) in which the alfalfa (Medicago sativa $\mathrm{L}$.) was planted by broadcast sowing (GP-B) and drilling (GP-D); (4) unplanted fallow plots with two different water regimes (PR), including long-term flooding (PR-I) and alternating wet and dry conditions (PRWD). In PR-I, long-term inundated soil was flooded with water for 2 years and in PR-DW, the plots were flooded for a season and then drained to dry during the following season. The general distance for intercropping was about $15 \mathrm{~cm}$.

The sampling time was just the growing period that not too early before the vegetables were harvested and not too late for the cutting of other plants for feeding stuff on October 20. Soil samples were collected from the top $15 \mathrm{~cm}$ of the soil profile using a soil corer. Five cores were collected from each plot and combined to give a composite sample. Shoots of five randomly selected plants were collected by cutting just above ground level within each plot and the roots of carrot and radish were also dug up for further analysis. Fresh plant samples were taken to the laboratory, immediately washed with tap water and rinsed with distilled water, and wiped dry with paper tissue. The plant and soil samples were then freeze-dried in a Free Zone 2.5 L Freeze Dry System (Labconco Corp., Kansas City, MO). The dried soil samples were grinded and sieved through a 60-mesh screen and the plant samples were homogenized in liquid nitrogen prior to storage at $-20{ }^{\circ} \mathrm{C}$ for subsequent analysis.

\section{PAE analysis reagent}

A mixed standard solution $(1 \mathrm{mg} / \mathrm{mL})$ composing 6 PAE compounds, namely dimethyl phthalate (DMP),
Fig. 1 Distribution map of sampling sites and e-waste recycling sites

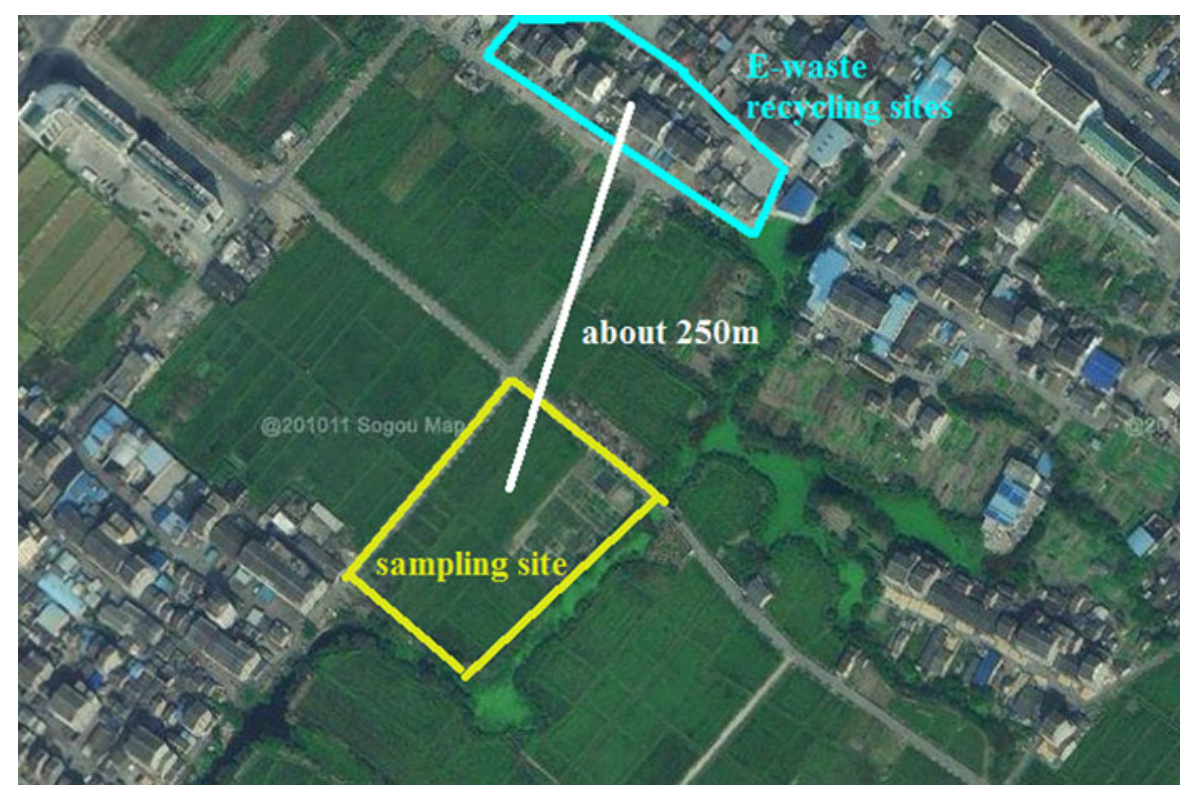






Fig. 2 Schematic drawings of the sampling site. For treatment abbreviations, CK means control fallow plots with no plants present; VP means vegetable plots in which carrot, soybean, cauliflower, radish and pak choi were intercropped in rows; GP$\mathrm{B}$ means green manure plots in which the alfalfa(Medicago sativa $\mathrm{L}$.) was planted by broadcast sowing and alfalfa planted by drilling for GP-D; PR means unplanted fallow plots

diethyl phthalate (DEP), butyl benzyl phthalate (BBP), di- $n$-butyl phthalate (DnBP), bis (2-ethylhexyl) phthalate (DEHP), di- $n$-octyl phthalate (DnOP) and the internal standard benzyl benzoate (BB, $5 \mathrm{mg} /$ $\mathrm{mL}$ ) were all obtained from AccuStandard, Inc., New Haven, CT. The six target pollutants were selected for study because they were nominated as priority pollutants by USEPA. Certified reference material CRM 136-100 (BNAs-Clay 1) was purchased from RT Corp., Laramie, WY, one of the original Proficiency Test providers recognized by USEPA and utilized in the analysis procedure for reliable test of the analysis method.

Analytical grade solvents (acetone and hexane) obtained from chemical reagent companies in Nanjing were re-distilled in an all-glass system to remove trace impurities before use. HPLC grade hexane was purchased from Tedia Company Inc., Fairfield, OH. Anhydrous sodium sulfate $\left(\mathrm{Na}_{2} \mathrm{SO}_{4}\right.$, reagent grade), neutral alumina $\left(\mathrm{Al}_{2} \mathrm{O}_{3}, 400\right.$ mesh and reagent grade), neutral silica gel (100-200 mesh) and sulfuric acid $\left(\mathrm{H}_{2} \mathrm{SO}_{4}\right.$, guaranteed reagent) were obtained from National Pharmaceutical Group Chemical Reagent Co., Ltd., Shanghai, China. The three column packing materials $\left(\mathrm{Na}_{2} \mathrm{SO}_{4}\right.$, neutral $\mathrm{Al}_{2} \mathrm{O}_{3}$ and neutral silica gel) were dried in a muffle furnace at $400{ }^{\circ} \mathrm{C}$ for $6 \mathrm{~h}$ and stored in desiccators before use.
Sample processing

Sample processing was conducted following the reliable method published by $\mathrm{Ma}$ et al. (2012b). Glassware was washed by the following procedure prior to analysis. After immersion and washing with soapy water in a laboratory ultrasonic washer and air drying, glassware with tick marks was immersed in sulfuric acid $\left(\mathrm{H}_{2} \mathrm{SO}_{4}, 98 \%\right.$, reagent grade) and washed with tap water, then rinsed with ultrapure water before oven drying at $50{ }^{\circ} \mathrm{C}$. Glassware without tick marks was baked for $6 \mathrm{~h}$ at $400{ }^{\circ} \mathrm{C}$ in a muffle furnace. All glassware was then thoroughly rinsed with acetone:hexane $(1: 1 \mathrm{v} / \mathrm{v})$ before use.

Ten grams of soil (or $1.00 \mathrm{~g}$ of plant sample) was placed in a clean glass centrifuge bottle, mixed on a vortex mixer for $1 \mathrm{~min}$ and immersed in $30 \mathrm{~mL}$ of acetone:hexane $(1: 1 \mathrm{v} / \mathrm{v})$ overnight. Spiked samples were prepared by adding $1 \mathrm{~mL}$ of $1 \mathrm{mg} / \mathrm{L}$ standard solution of 6 target PAEs to the soil (or $0.1 \mathrm{~mL}$ to the plant sample) before analysis following the same procedure. Ultrasonic extraction was carried out the next day in a water bath at $25^{\circ} \mathrm{C}$ for $30 \mathrm{~min}$ with $100 \%$ power before centrifuging at $1,500 \mathrm{rpm}$ for $5 \mathrm{~min}$. The three supernatants were all filtered into a round-bottom flask after another two extractions with $20 \mathrm{~mL}$ of acetone: hexane $(1: 1 \mathrm{v} / \mathrm{v})$ for $15 \mathrm{~min}$ each. About $70 \mathrm{~mL}$ of liquid in the flask was reduced by rotary evaporation to $1-2 \mathrm{~mL}\left(350 \mathrm{mbar}, 40{ }^{\circ} \mathrm{C}\right.$ water bath, $80 \mathrm{rpm})$. Hexane (3-4 mL) was added to the remaining solvent and rotary evaporation was continued to a volume less than $1 \mathrm{~mL}$ but not to dryness.

Column chromatography was performed in a glass column $(1 \times 26 \mathrm{~cm})$ with $2 \mathrm{~g}$ of $\mathrm{Na}_{2} \mathrm{SO}_{4}, 6 \mathrm{~g}$ of neutral $\mathrm{Al}_{2} \mathrm{O}_{3}$ and $12 \mathrm{~g}$ of neutral silica gel (from bottom to top). Pre-washing was with $15 \mathrm{~mL}$ of hexane and $15 \mathrm{~mL}$ of acetone:hexane (1:4 v/v) mixture before sample loading and elution with $40 \mathrm{~mL}$ of acetone:hexane $(1: 4 \mathrm{v} / \mathrm{v})$. All the washing solutions were collected and reduced to less than $1 \mathrm{~mL}$ by rotary evaporation as described above. Plant samples with heavy plant pigment were further washed with sulfuric acid (Meng et al. 1996) and concentrated to less than $1 \mathrm{~mL}$. Ten microliters of internal standard (BB) was added before hexane (HPLC grade) was added to bring the final volume to $1 \mathrm{~mL}$. Samples were transferred to brown sample bottles and stored at $-20{ }^{\circ} \mathrm{C}$ before further analysis. 
Instrumental analysis

Analysis of individual PAEs in samples was performed by a modification of USEPA method 8270C (1996) with an Agilent 7890GC-5975 MSD gas chromatograph-mass spectrometer (Ma et al. 2012b). Samples were resolved on a DB-5 (30 $\mathrm{m} \times$ $0.25 \mathrm{~mm} \times 0.25 \mu \mathrm{m})$ fused-silica capillary column with helium (purity $>99.999 \%$ ) as carrier gas at $1.2 \mathrm{~mL} / \mathrm{min}$. The injector temperature was set at $250{ }^{\circ} \mathrm{C}$. The GC temperature program featured an initial column temperature of $50{ }^{\circ} \mathrm{C}$ which was held for $1 \mathrm{~min}$, with a ramp of $15^{\circ} \mathrm{C} / \mathrm{min}$ to $200{ }^{\circ} \mathrm{C}$ which was held for $1 \mathrm{~min}$, then $8{ }^{\circ} \mathrm{C} / \mathrm{min}$ ramp to $280{ }^{\circ} \mathrm{C}$ which was held for $3 \mathrm{~min}$. Post-run was at $285^{\circ} \mathrm{C}$ for $2 \mathrm{~min}$. Under selected ion monitoring mode, nonpulse injection with a volume of $1.0 \mu \mathrm{L}$ each in splitless mode was carried out. The GC-MS transfer line was set at $280{ }^{\circ} \mathrm{C}$.

Quality assurance and quality control

During analysis, whole procedure blanks, soil matrix blanks, spiked soil matrix and parallel samples were all employed, together with analysis of the certified reference material to ensure the reliability of the analysis (Ma et al. 2012b). The recovery rates of spiked soils matrix at $100 \mu \mathrm{g} / \mathrm{kg}$ (DW) were between 75.88 and $107.61 \%$, with RSD of 3.88-8.91. Instrument detection limits (IDLs) for 6 target compounds were $0.11-0.35 \mu \mathrm{g} / \mathrm{L}$, and method detection limits (MDLs) were $68-135 \mu \mathrm{g} / \mathrm{kg}$. Linearity of response between 0.02 and $2 \mathrm{mg} / \mathrm{L}$ showed $R^{2}$ (correlation coefficient) values of the calibration curve $>0.999$. BB was used as the internal standard to allow high accuracy and sensitivity. Analysis of the CRM also showed the reliability of the results (Ma et al. 2012b). For every 16 samples, 2 whole procedure blanks, 2 soil matrix blanks and 1 CRM 136-100 were analyzed.

Health risk assessment

\section{Risk assumption}

The main source of PAEs was assumed to be soil ingestion and eating intake in this experiment. PAE concentrations in soil samples were mainly used for soil ingestion exposure assessment pathways and risk characterization of local people; PAE concentrations in vegetables were mainly used for intake exposure assessment. The intake consumption estimates of vegetables were based on the dietary intake data published by the Environment Agency and Department of Environment, Food and Rural Affairs (2002) Danish Nationwide Dietary Survey in CLEA (the contaminated land exposure assessment) of London with slight modification and divided into age groups of 0-6 (refer to the data of 1-4 of CLEA) and 6-70 as shown in Table 1.

\section{Exposure assessment}

The amount of PAE intake by soil ingestion and skin contact with soil can be calculated as:

$\mathrm{In}_{\text {soil }}=\frac{\mathrm{EF} \times \mathrm{ED} \times \mathrm{IR}_{\text {soil }} \times \mathrm{C}_{s} \times \mathrm{CF}}{\mathrm{BW} \times \mathrm{AT} \times 365} \quad[\mu \mathrm{g} /(\mathrm{kg} \mathrm{BW} \mathrm{d})]$

where EF is the exposure frequency (day/year); $\mathrm{ED}$ is the exposure cycle (year); $\mathrm{IR}_{\text {soil }}$ is the intake rate of soil (mg/day); $\mathrm{C}_{s}$ is the concentration of individual PAE compounds in the soil $(\mu \mathrm{g} / \mathrm{kg})$; $\mathrm{CF}$ is a conversion factor $\left(10^{-6} \mathrm{~kg} / \mathrm{mg}\right)$; BW is the body weight $(\mathrm{kg})$ and AT is the average time (year).

The intake by food consumption can be calculated as:

$$
\begin{aligned}
& \operatorname{In}_{\text {food }} \\
& =\text { daily vegetable intake } \times \mathrm{R}_{v} \times \mathrm{C}_{f} \quad[\mu \mathrm{g} /(\mathrm{kg} \mathrm{BW} \mathrm{d})]
\end{aligned}
$$

where daily vegetable intake $[\mathrm{g} /(\mathrm{fw} \mathrm{kg}$ BW day $)]$ is as shown in Table $1 ; \mathrm{R}_{v}$ is the ratio of fresh and dry vegetables and $\mathrm{C}_{f}$ is the concentration of individual

Table 1 Summary consumption rates of vegetables used in

\begin{tabular}{|c|c|c|c|}
\hline \multirow{2}{*}{$\begin{array}{l}\text { Age } \\
\text { (years) }\end{array}$} & \multicolumn{3}{|c|}{ Daily vegetable intake $[\mathrm{g} /(\mathrm{FW} \mathrm{kg} \mathrm{BW}$ day)] } \\
\hline & $\begin{array}{l}\text { Salad leafy } \\
\text { vegetables }\end{array}$ & Carrot & $\begin{array}{l}\text { Wild } \\
\text { cabbage }\end{array}$ \\
\hline $0-6$ & 0.32 & 0.62 & 0.44 \\
\hline $6-70$ & 0.16 & 0.27 & 0.30 \\
\hline $0-6$ & 0.037 & 0.125 & 0.051 \\
\hline $6-70$ & 0.019 & 0.054 & 0.035 \\
\hline
\end{tabular}
CLEA according to age class 
PAE compounds in the food which is mainly the vegetables $(\mu \mathrm{g} / \mathrm{kg})$.

\section{Risk characterization}

Index of risk (IR) is the sum of multi-exposure to pollutants and it can be calculated as:

$\mathrm{IR}_{j}=\sum \mathrm{IR}_{i} \quad(i=1,2,3 \ldots \ldots)$

$\mathrm{HQ}=\frac{\text { Intake }}{\text { RfDo }}$

where HQ is the Hazard Quotient, which is defined as the relation between the predicted exposure and the oral reference dose (RfDo). Intake is the exposure amount and RfDo is the reference amount of each individual pollutant $[\mathrm{mg} /(\mathrm{kg}$ day $)]$.

\section{Statistics analysis}

All the data were processed with Microsoft Excel 2003 and the SPSS v.14.0 software package. Chemical concentrations under the limit of detection (LOD) were assumed to be at a concentration of one-third of that value (ND-1/3 LOD). The data were analyzed for significant differences from the control treatment or between treatments using one-way analysis of variance. The level of significance was set at a probability lower than $0.05(p<0.05)$.

\section{Results and discussion}

Target PAE compounds in soil samples

Figure 3 shows the concentrations of the six target PAEs in soil samples under the different treatments. The residual total PAE concentrations in test soils are followed the order, CK $>$ PR-I $>$ PR-DW $>$ GP$\mathrm{D}>\mathrm{GP}-\mathrm{B}>\mathrm{VP}$, with concentrations of 2.39, 2.24, $1.68,0.54,0.47$ and $0.31 \mathrm{mg} / \mathrm{kg}$, and except for PR-I, PAE concentrations in all the treatment were significantly reduced by about $29.8-87.0 \%$ (Table 2). The major contaminants determined were DEHP and DnBP and their removal rates were also the highest found in most treatments (Table 2).

Based on the determined results, the presence of plants, especially vegetables and alfalfa (under both broadcast sown and drilled), appeared to accelerate the removal of PAEs in the soil, with a removal rate of about 3/4 of total PAE compounds compared with the control soil. On account of this, phytoremediation with alfalfa might be a recommended approach for cleanup of soils contaminated with PAE compounds in the future in addition to its customary role as green manure, especially by broadcast sowing, which showed higher efficiency of PAE removal (Fig. 3). The possible reason for the variety between two sowing methods could be that broadcasting sowing may have spread the seeds more evenly across the plots to make more efficient

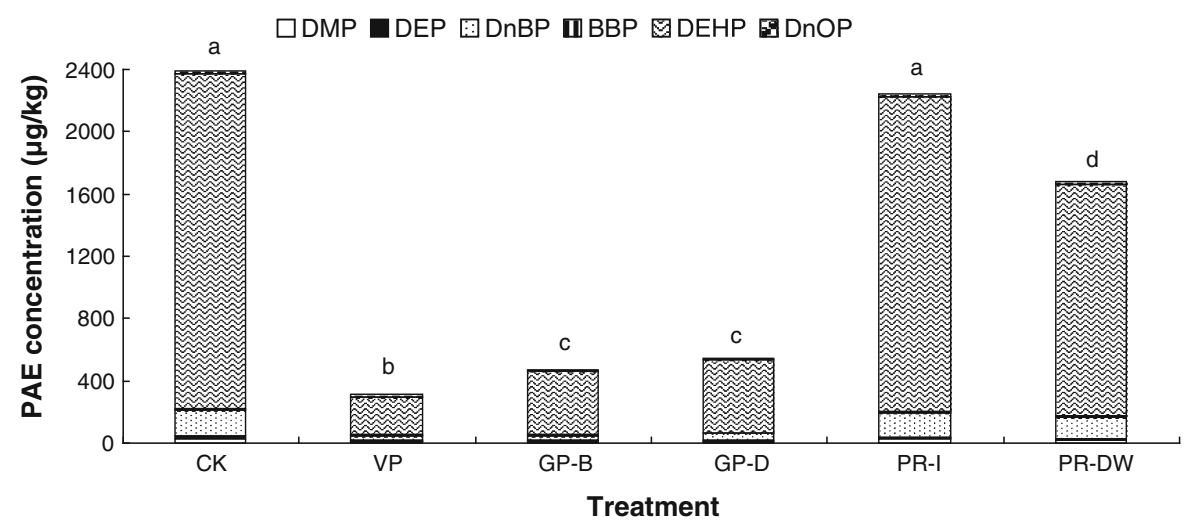

Fig. 3 PAE concentrations in soil samples under the different experimental treatments $(\mu \mathrm{g} / \mathrm{kg} \mathrm{DW})$. For treatment abbreviations, CK means control fallow plots with no plants present; VP means vegetable plots in which carrot, soybean, cauliflower, radish and pak choi were intercropped in rows; GP means green manure plots in which the alfalfa (Medicago sativa L.) was planted by broadcast sowing (GP-B) and drilling (GP-D); PR means unplanted fallow plots with two different water regimes, including long-term flooding (PR-I) and alternating wet and dry conditions (PR-WD). Each point is the mean of three replicates. Different letters in columns indicate significant difference at $p<0.05$ between treatments 
Table 2 Removal rate of PAE compounds in soils of different treatment plots

\begin{tabular}{llllrl}
\hline $\begin{array}{l}\text { Removal } \\
\text { efficiency }(\%)\end{array}$ & \multicolumn{4}{l}{ Treatment } \\
\cline { 2 - 6 } & VP & GP-BS & GP-D & PR-I & PR-DW \\
\hline DMP & 69.13 & 67.92 & 72.42 & 15.56 & 28.82 \\
DEP & 60.51 & 13.42 & 38.96 & 26.04 & 39.31 \\
DnBP & 78.03 & 83.10 & 72.87 & 1.24 & 16.60 \\
BBP & 70.47 & 33.81 & 29.22 & 14.82 & 17.25 \\
DEHP & 88.82 & 81.02 & 78.25 & 6.23 & 30.95 \\
DnOP & 21.58 & 58.71 & 69.34 & 20.80 & 12.02 \\
Total & 87.02 & 80.23 & 77.29 & 6.27 & 29.75 \\
\hline
\end{tabular}

For treatment abbreviations, see caption of Fig. 1

use of the field area. Drill sowing creates rows of plants separated by bare soil and this lowers the total biomass of alfalfa and reduces efficiency of utilization of the planted area.

Photodecomposition, hydrolysis and biodegradation by native microorganisms are among the main factors influencing PAE degradation under different physical conditions. PAE concentrations also decreased under flooded and dry-wet moisture regimes compared with control soil by about 6.3 and $30 \%$, respectively. Since the only difference between these treatments was soil moisture regime, we can conclude that both photodecomposition and hydrolysis of PAEs proceed very slowly and the key method to eliminate the pollutants is the biodegradation approach (Wolfe et al. 1980). Most PAEs are readily degraded under aerobic conditions but much more slowly in anaerobic environments, especially in the case of DEHP and DnOP (Ziogou et al. 1989; Wu et al. 2010; Yuan et al. 2010). Under flooded conditions, the degradation of all the target pollutants is slowed down by oxygen limitation, and the soil would continue to receive contamination by atmospheric deposition. In contrast, flooded conditions followed by dry conditions might provide the opportunity for indigenous aerobic and microaerophilic microorganisms to degrade PAEs when suitable redox conditions occur in the soil during the dry season. Thus, the removal rates of total PAE compounds increased to about fivefold in treatment PR-DW compared with PR-I, with the removal rate of DEHP particularly affected.

Except for the great elimination effect by alfalfa, the relatively high removal of PAE compounds by vegetables was also notable, with $87.0 \%$ removal of target pollutants compared with the control soil. Vegetables may therefore be useful in contaminant removal providing that they do not consequently pose an unacceptable risk to human health through the food chain.

Target PAE compounds in plant samples

The most notable difference between soil samples and plant samples was the proportions of different target pollutants. Particularly in vegetables, the proportion of DnOP increased over DEHP and DnBP in some plants. However, in the alfalfa plots, DEHP and DnBP remained the two major PAEs in the shoots, similar to the soil samples (Fig. 4). The general order of the total concentrations of the six target PAEs in plants and plant parts was alfalfa $>$ edible parts of vegetables in underground stem $>$ vegetable leaves (Fig. 4).

It is well known that atmospheric deposition is a source of soil PAEs and this may have been one of the sources of the PAEs in our test plants. In the view of the uncertainty caused by windiness during this time of the year, such as the wind power and wind direction alteration, regional monitor of atmospheric results of PAE compounds contamination could not provide confirming data for evaluation of PAE resource and human health risk assessment, so this part was discussed without determined data. According to previous studies, leafy vegetables might accumulate more organic pollutants because of their large surface area exposed to the atmosphere (Ryan et al. 1988). Nevertheless, in the present investigation, PAE concentrations in leafy vegetables tended to be lower than in root vegetables, similar with the conclusion achieved by Liu et al. (2010a) and Top et al. (1986). The possible reason might be that organic chemicals with higher vapor pressure such as DEHP and DnOP are more apt to exchanges on leaf interface, including more absorption and volatilization through leaves to the whole plant (Liu et al. 2010a), so that more volatilization of these pollutants also exists at the same time. This could be the explanation to the less net accumulation of some PAE components in this study and the main factor affected the concentration level of PAEs in test plants (Top et al. 1986). This may also suggest that the soil was the main source of PAE pollution to the plants but the relatively small leaf area of pak choi may have minimized the contribution of 


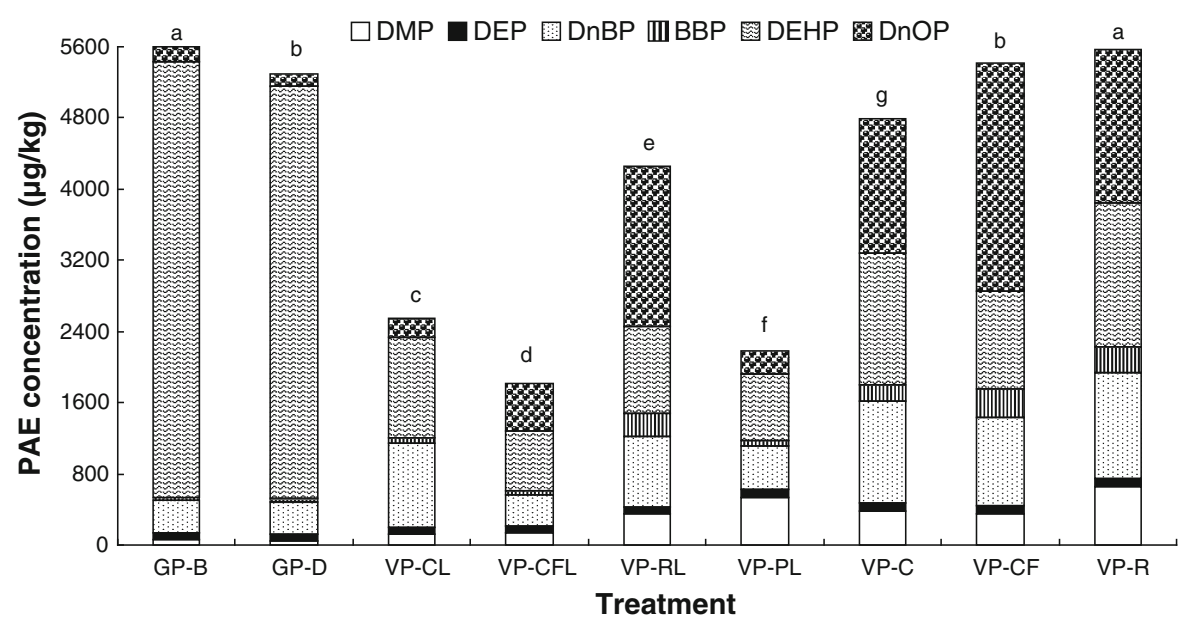

Fig. 4 PAE concentrations in plant samples under different experimental treatments $(\mu \mathrm{g} / \mathrm{kg} \mathrm{DW})$. For treatment abbreviations, see caption of Fig. 2, 3. In vegetable plots (VP), CL means carrot leaves; CFL, cauliflower leaves; RL, radish leaves; PL,

atmospheric deposition to PAE accumulation in the plants. The higher concentrations in radish leaves with their higher surface area would support this conclusion. The large accumulation of PAEs by alfalfa is likely due to its relatively large shoot biomass.

The high concentrations of total PAEs in all test plants are noteworthy, ranging from about $1.81-5.60 \mathrm{mg} / \mathrm{kg}$ DW, especially in GP-B, VP-R and VP-CF, which were around $5.5 \mathrm{mg} / \mathrm{kg} \mathrm{DW}$, more than twice the concentration in soil of the control treatment (Fig. 4). This indicates that a high capability for PAE accumulation may offer a good practical prospect for phytoremediation using species such as alfalfa; the vegetables show less promise in this regard. In vegetables, the total concentrations of the 6 pollutants were about $2 \mathrm{mg} / \mathrm{kg} \mathrm{DW}$, and some, notably the edible parts of carrot, radish and cauliflower, were over $4 \mathrm{mg} / \mathrm{kg}$ DW. Different plant species have different abilities to accumulate PAEs, and here, the leafy vegetables showed lower capacities than root or stem vegetables. The explanation for radish edible parts having the largest concentration of the target pollutants might be its large water content. Carrot has a high lipid content and oil channels in the root which generates greater potential for the uptake of relatively non-polar chemicals (Wild and Jones 1992; Wang and Jones 1994; Kipopoulou et al. 1999). This may also explain the high $\mathrm{BCF}$ of $\mathrm{BBP}$ and DnOP in carrot roots. pak choi leaves; $\mathrm{C}$, carrot edible root; $\mathrm{CF}$, cauliflower edible parts; and R, radish edible root. Each point is the mean of three replicates. Different letters in columns show significant difference at $p<0.05$ level between treatments

DnOP, DEHP and DnBP were generally the three major PAE compounds in all vegetable samples. Interestingly, the higher the total concentrations of the 6 PAEs, the higher the concentrations of DnOP and DEHP, especially in radish, cauliflower, carrot and radish leaves. In the edible parts of vegetables, higher lipid content might result in higher concentrations of the target pollutants and in radish, the large surface area may be an additional factor.

BCFs of target pollutants in vegetables

Almost all the BCFs of individual pollutants in the monitored plants were around 20 (Fig. 5). DnOP showed very high BCFs in every vegetable sample, followed by BBP, but the BCFs of DEHP were relatively low. Both DnOP and DEHP are high molecular weight compounds and their BCFs would be expected to be similar. The observed differences in their BCFs might be due to their sources. DnOP concentrations were not pronounced in soil samples but were relatively high in the leaves and edible parts of vegetables, indicating the main sources of this target compound was from the atmosphere, because only via the supply of DnOP from the soil up to the leaves and so on would not have resulted in such high concentration of DnOP in plant leaves. However, also as compounds with long alkyl chain, DEHP suggested a different approach in transferring. DEHP 


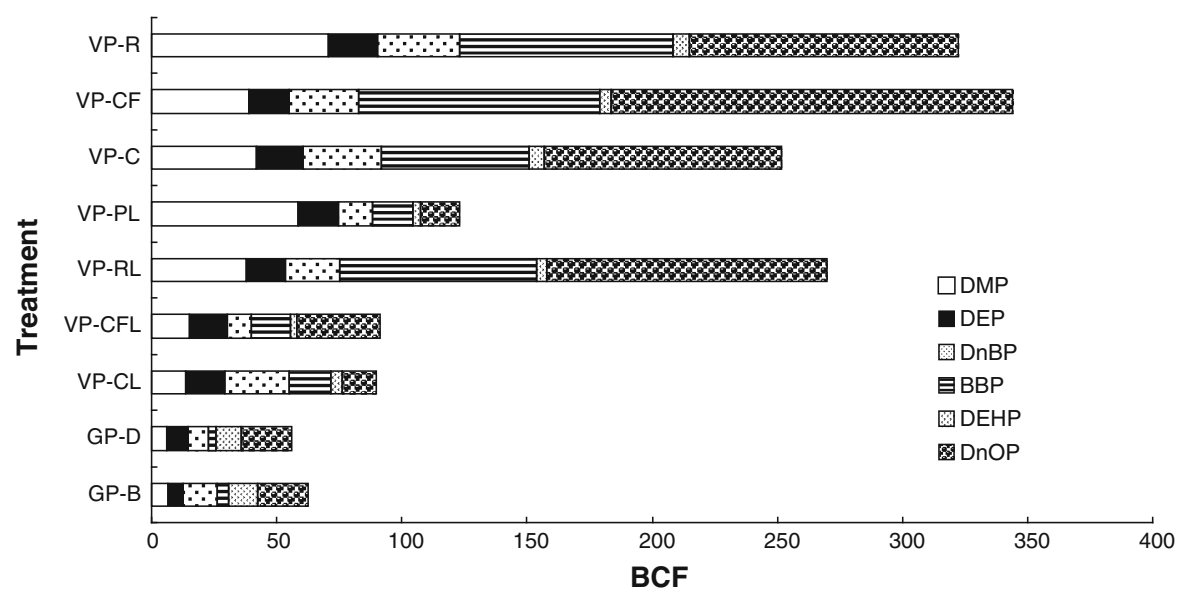

Fig. 5 BCFs of different plant species under different experimental treatments (DW). For treatment abbreviations, see caption of Fig. 2, 3. Each point is the mean of three replicates

concentration in soil was not low, but that in the plant parts above ground was relative low. DEHP was difficult to transfer between different matrices, so even if the contents in the soil was not low, the concentration of DEHP that transferred up to the leaves and so on was very low, so that its BCF was very small compared with DnOP. The high BCFs of the vegetables, and especially the edible parts with values almost 2-3 times larger than the leaves, indicate that they may represent a threat to human safety via the food chain and this source of exposure requires serious consideration.

Health risk assessment of PAEs in the edible parts of vegetables

In common green manure like alfalfa, the great ability of accumulation in PAE target pollutants could be utilized as a strong suit for the prospect of being a phytoremediation policy. However, as to the vegetables, more serious problems might appear. Local people would eat their self-produced vegetables without noticing that different contaminants such as environmental hormone pollutants PAEs were concentrated in vegetables and these contaminants might be transferred into human body and cause further damage. The monitored results of the total concentrations of the six pollutants in the edible parts of carrot, radish and cauliflower exceeded $4 \mathrm{mg} / \mathrm{kg}$ DW and this should generate concern about the risk of PAE exposure to humans consuming contaminated vegetables.
On the calculation of hazard quotient (HQ), reference exposure frequency values were 350 days/year and the exposure cycle was 70 year according to USEPA under agriculture and habitation use (Kluwe 1982). The intake rate of soil was set at $100 \mathrm{mg} /$ day for people under age 6 and $200 \mathrm{mg} /$ day for older individuals (USEPA 1996). According to previous investigations in China, the average body weights of a 6-year-old child and an adult are 13.6 and $60 \mathrm{~kg}$, respectively. Dietary intakes of pak choi, carrot, cauliflower and radish corresponding to those of salad use leafy vegetables, carrot, wild cabbage and potato are listed in Table 1. HQ values of DEHP are over 1 both for children under 6 years old and older persons, and that of DnBP is much higher than of other pollutants although well below 1 (Table 3 NMED 2004; USEPA). However, none of the four target pollutants has reached its TDI value (Table 4). The HQ value for children under 6 is much higher than 1 , indicating that DEHP may pose a risk to the health of children under 6 solely by soil ingestion or vegetable intake without considering the risk of water intake and air inhalation, both of which must be included for the complex occurrence of PAE compounds in different environment media. Thus, consumption of vegetables produced in soils impacted by electronic waste dismantling facilities is potentially hazardous.

Although the HQ of DEHP was estimated to be over 1 , it has been reported that about $90 \%$ of pollutants such as DEHP in foods can be hydrolyzed by enzymes from the intestines and pancreas and the remaining $10 \%$ can be lost during the process of cooking 
Table 3 Calculated risk index of 6 PAE target pollutants

\begin{tabular}{|c|c|c|c|c|c|c|c|}
\hline \multirow[t]{2}{*}{ PAE } & \multirow[t]{2}{*}{$\begin{array}{l}\text { RfDo } \\
{[\mathrm{mg} /(\mathrm{kg} \text { day })]}\end{array}$} & \multicolumn{2}{|c|}{$\begin{array}{l}\mathrm{In}_{\text {soil }} \\
{[\mu \mathrm{g} /(\mathrm{kg} \text { BW day })]}\end{array}$} & \multicolumn{2}{|c|}{$\begin{array}{l}\mathrm{In}_{\text {food }} \\
{[\mu \mathrm{g} /(\mathrm{kg} \text { BW day })]}\end{array}$} & \multicolumn{2}{|c|}{ HQ [mg/(kg day)] } \\
\hline & & $0-6$ & $6-70$ & $0-6$ & $6-70$ & $0-6$ & $6-70$ \\
\hline DMP & 10 & 2.45 & 0.49 & 0.028 & 0.003 & 0.00025 & 4.93E-05 \\
\hline DEP & 0.8 & 1.06 & 0.21 & 0.012 & 0.001 & 0.00134 & 0.00026 \\
\hline DnBP & 0.1 & 13.58 & 2.71 & 0.156 & 0.016 & 0.13736 & 0.02726 \\
\hline BBP & 0.2 & 0.92 & 0.18 & 0.011 & 0.001 & 0.00466 & 0.00091 \\
\hline DEHP & 0.02 & 176.88 & 35.36 & 2.037 & 0.205 & 8.94585 & 1.77825 \\
\hline DnOP & 0.04 & 1.68 & 0.34 & 0.019 & 0.002 & 0.042475 & 0.00855 \\
\hline
\end{tabular}

Table 4 Comparison of evaluated intake amounts with TDI of the 6 PAE target pollutants

\begin{tabular}{llll}
\hline PAE & $\begin{array}{l}\text { TDI } \\
{[\mu \mathrm{g} /(\mathrm{kg} \text { day })]}\end{array}$ & \multicolumn{2}{l}{ Daily intake $[\mu \mathrm{g} /(\mathrm{kg}$ day $)]$} \\
\cline { 3 - 4 } & & Age 0-6 & Age 6-70 \\
\hline DMP & & 0.182 & 0.008 \\
DEP & & 0.079 & 0.004 \\
DnBP & 100 & 1.01 & 0.045 \\
BBP & 850 & 0.068 & 0.003 \\
DEHP & 50 & 13.16 & 0.593 \\
DnOP & 370 & 0.125 & 0.006 \\
\hline
\end{tabular}

NMED (2004)

(Mikula et al. 2005) and this may ameliorate the risk to a more controllable level. The risk of other target compounds to human health may also be controllable if they can be hydrolyzed and lost during cooking.

Further investigation is required to produce a more accurate health risk assessment of electronic waste recycling areas, including studies on concentrations and components of PAE compounds in groundwater and the atmosphere. Since simultaneous daily contact with more than two PAEs occurs continually and interactions between PAE pollutants have not been investigated are therefore not understood, the potential risk of indirect damage to human health requires urgent attention.

\section{Conclusions}

Results indicated that contamination of six PAEs occurred near an e-waste dismantling area at the level of $\mathrm{mg} / \mathrm{kg}$ in soil and plant samples (including vegetables). DEHP may represent a high-exposure risk to consumers of all ages only by soil ingestion and vegetable intake, let alone considering other contamination resources such as drinking water, dermal contact and so on in authoritative health risk assessment in this area. Atmospheric deposition is another important source of some PAE compounds such as DnOP. Phytoremediation with alfalfa for PAE soil contamination could be counted as an environmental friendly method in PAEs elimination in the future, especially by broadcast sowing. Environmental health problems at electronic waste recycling area require further more investigation for the complexity of the contamination by persistent organic pollutants resulting from uncontrolled and unregulated industrial practices.

Acknowledgments This research was supported by the National Environmental Protection Special Funds for Scientific Research on Public Causes of China (201109018 and 2010467016).

\section{References}

Cai, Q. Y., Mo, C. H., Wu, Q. T., et al. (2008a). Polycyclic aromatic hydrocarbons and phthalic acid esters in the soilradish (Raphanus sativus) system with sewage sludge and compost application. Bioresource Technology, 99(6), 1830-1836.

Cai, Q. Y., Mo, C. H., Wu, Q. T., et al. (2008b). The status of soil contamination by semivolatile organic chemicals (SVOCs) in China: A review. Science of the Total Environment, 389(2-3), 209-224.

Cai, Z. M., Wang, F. H., Zhao, W. H., et al. (2003). Determination of PAEs in food made of livestock internal organs. Journal of Tongji University (Medical Science), 5, 395-397.

Chen, D. H., Li, L. P., Bi, X. H., et al. (2008). PBDEs pollution in the atmosphere of a typical e-waste dismantling region. Environmental Science, 8(29), 2105-2110.

Chi, J. (2009). Phthalate acid esters in Potamogeton crispus L. from Haihe River, China. Chemosphere, 77(1), 48-52.

Duty, S. M., Singh, N. P., Silva, M. J., et al. (2003). The relationship between environmental exposures to phthalates and 
DNA damage in human sperm using the neutral comet assay. Environmental Health Perspective, 111(9), 1164-1169.

Gray, L. E., Jr, Ostby, J., Price, J. F. M., et al. (2000). Perinatal exposure to the phthalates DEHP, BBP, and DINP, but not DEP, DMP, or DOTP, alters sexual differentiation of the male rat. Toxicological Sciences, 58(2), 350-365.

Kelly, B. C., Ikonomou, M. G., Blair, J. D., et al. (2007). Food web-specific biomagnification of persistent organic pollutants. Science, 317(5835), 236-238.

Kipopoulou, A. M., Manoli, E., \& Samara, C. (1999). Bioconcentration of polycyclic aromatic hydrocarbons in vegetables grown in an industrial area. Environmental Pollution, 106(3), 369-380.

Kluwe, W. M. (1982). Overview of phthalate ester pharmacokinetices in mammalian species. Environmental Health Perspective, 45, 3-9.

Li, Y. M., Jiang, G. B., Wang, Y., et al. (2008a). Pollution level and phase partition regulation of PCDD/Fs, PCBs and PBDEs in atmosphere of e-waste recycling sites. Science China Press, 2(53), 165-171.

Li, X., Nie, X. P., Pan, D. B., et al. (2008b). Analysis of PAEs in muscle tissue of freshwater fish from fishponds in Pearl River Delta. Journal of Environmental and Health, 25(3), 202-205.

Liao, C. S., Yen, J. H., \& Wang, Y. S. (2009). Growth inhibition in Chinese cabbage (Brassica rapa var. chinensis) growth exposed to di-n-butyl phthalate. Journal of Hazardous Materials, 163(2-3), 625-631.

Liu, H., Liang, Y., Zhang, D., et al. (2010a). Impact of MSW landfill on the environmental contamination of phthalate esters. Waste Management, 30(8-9), 1569-1576.

Liu, W. L., Shen, C. F., Zhang, Z., et al. (2009). Distribution of phthalate esters in soil of e-waste recycling sites from Taizhou city in China. Bulletine of Environmental Contamination and Toxicology, 82(6), 665-667.

Liu, W. L., Zhang, Z., Zhu, L. Q., et al. (2010b). Distribution characteristics of phthalic acid esters in soils and plants at e-waste recycling sites in Taizhou of Zhejiang, China. Chinese Journal of Applied Ecology, 2(21), 489-494.

Ma, T. T., Luo, Y. M., Christie, P., et al. (2012a). Removal of phthalic esters from contaminated soil using different cropping systems: A field study. European Journal of Soil Biology, 50, 76-82.

Ma, T. T., Teng, Y., Christie, P., et al. (2012b). A new procedure combining GC-MS with accelerated solvent extraction for analysis of soils contaminated with phthalic acid esters. Frontiers of Environmental Science and Engineering, . doi: 10.1007/s11783-012-0463-2.

Matsumoto, M., Hirata-Koizumi, M., \& Ema, M. (2008). Potential adverse effects of phthalic acid esters on human health: A review of recent studies on reproduction. Regulatory Toxicology and Pharmacology, 50(1), 37-49.

Meng, P. R., Wang, X. K., Xu, G. T., et al. (1996). Study about the clean up method of PAEs in the soil. Journal of Shandong Institute of Building Materials, 10(2), 15-18.

Mikula, P., Svobodová, Z., \& Smutná, M. (2005). Phthalates: Toxicology and food safety-a review. Czech Journal of Food Sciences, 23(6), 217-223.

Nanni, N., Fiselier, K., Grob, K., et al. (2011). Contamination of vegetable oils marketed in Italy by phthalic acid esters. Food Control, 22(2), 209-214.
Ni, J. Z., Luo, Y. M., Wei, R., et al. (2008). Research on soil environmental quality and remediation of the Yangtze River delta region V. polycyclic aromatic hydrocarbons (PAHs) contamination status and source apportionment in agricultural soils of typical areas. Acta Pedologica Sinica, 45(2), 234-239.

NMED (New Mexico Environment Department), Hazardous Waste Bureau Ground Water Quality Bureau and Voluntary Remediation Program. (2004). Technical background document for development of soil screening levels revision 2.0 .

Ryan, J. A., Bell, R. M., Davidson, J. M., et al. (1988). Plant uptake of non-ionic organic chemicals from soils. Chemosphere, 17(12), 2299-2323.

Shanker, R., Ramakrishma, C., \& Seth, P. K. (1985). Degradation of some phthalic acid esters in soil. Environmental Pollution Series A, Ecological and Biological, 39(1), 1-7.

The Environment Agency and Department of Environment, Food and Rural Affairs. (2002). CLEA (The contaminated land exposure assessment) model: Technical basis and algorithms. London.

Top, E., Scheunert, I., Attar, A., et al. (1986). Factors affecting the uptake of 14C-labeled organic chemicals by plants from soil. Ecotoxicology and Environmental Safety, 11, 219-228.

USEPA. (1996). Soil screening guidance: User's guide.

USEPA Method 8270C. (1996). Semivolatile organic compounds by gas chromatography/mass spectrometry (GC/ MS).

USEPA. The risk assessment information system: Chemical database. Available on line: http://rais.ornl.gov/cig-bin/ tox/TOX_select?select=nrad.

Wang, M. J., \& Jones, K. C. (1994). Uptake of chlorobenzenes by carrots from spiked and sewage sludge-amended soil. Environmental Science and Technology, 28(7), 1260-1267.

Wang, F., Xia, X. H., \& Sha, Y. J. (2008). Distribution of phthalic acid esters in Wuhan section of the Yangtze River, China. Journal of Hazardous Materials, 154(1-3), 317-324.

Wild, S. R., \& Jones, K. C. (1992). Polynuclear aromatic hydrocarbons uptake by carrots grown in sludge amended soil. Journal of Environmental Quality, 21(2), 217-225.

Wolfe, N. L., Burns, L. A., \& Steen, W. C. (1980). Use of linear free energy relationships and an evaluative model to assess the fate and transport of phthalate esters in the aquatic environment. Chemosphere, 9(7-8), 393-402.

Wu, X. L., Liang, R. X., Dai, Q. Y., et al. (2010). Complete degradation of di-n-octyl phthalate by biochemical cooperation between Gordonia sp. strain JDC-2 and Arthrobacter sp. strain JDC-32 isolated from activated sludge. Journal of Hazardous Materials, 176(1-3), 262-268.

Xia, X. H., Yang, L. Y., Bu, Q. W., et al. (2011). Levels, distribution, and health risk of phthalate esters in urban soils of Beijing, China. Journal of Environmental Quality, 40(5), 1643-1651.

Yuan, S. Y., Huang, I. C., \& Chang, B. V. (2010). Biodegradation of dibutyl phthalate and di-(2-ethylhexyl) phthalate and microbial community changes in mangrove sediment. Journal of Hazardous Materials, 184(1-3), 826-831.

Zeng, F., Cui, K. Y., Xie, Z. Y., et al. (2009a). Distribution of phthalate esters in urban soils of subtropical city, 
Guangzhou, China. Journal of Hazardous Materials, 164(2-3), 1171-1178.

Zeng, F., Wen, J. X., Cui, K. Y., et al. (2009b). Seasonal distribution of phthalate esters in surface water of the urban lakes in the subtropical city, Guangzhou, China. Journal of Hazardous Materials, 169(1-3), 719-725.

Zhang, Z. H., Jin, S. W., Duan, J. M., et al. (2010a). Surface soil contamination levels of phthalates in Taizhou electronic waste disposing district. Journal of Wuhan Institute of Chemical Technology, 32(7), 28-32.

Zhang, Z. H., Jin, S. W., Wan, P., et al. (2010b). Determination of phthalates in e-waste samples. China Resources Comprehensive Utilization, 7, 24-26.

Ziogou, K., Kirk, P. W. W., \& Lester, J. N. (1989). Behaviour of phthalic acid esters during batch anaerobic digestion of sludge. Water Research, 23(6), 743-748. 